\title{
УДК 504.052
}

\section{Экологический блок анкетного исследования жителей сельских территорий}

\author{
Канд. с.-хоз. наук Полухина М.Г. redhvost@yandex.ru \\ Федеральный научный центр зернобобовых и крупяных культур \\ 302502, Орловская область, Орловский район, пос. Стрелецкий, ул. Молодежная, 10
}

Объектом исследования стали сельские жстели, прожсиающце в 5 муниципальных районах (Мценском, Сосковском, Шаблыкинском, Глазуновском, Болховском) Орловской области, представляющие все природно-экономические зоны (Западную, Центральную и Юго-Восточную). Предметом исследования явились экологические проблемы жсителей сельских территорий, оказывающих непосредственное влияние на развитие сельской территории в конкретно взятом регионе. Целью исследования ставилось проведение анкетирования сельских жсителей для определения влияния хозяйственной деятельности человека на экологию, а так же влияния экологической ситуации на устойчивое развитие сельских территорий, качество жжизни селян. Определить экологические проблемы и пути их решения, а так жее их значимости для сельских жсителей, относительно проблем социального и экономического характера. Для изучения мнения сельских жителей об экологическом состоянии сельской территории и направлениях дальнейшего развития была разработана анкета. Анкетирование сельских жстелей проводились в два этапа, в 2013 и 2018 годах, для получения данных в динамике. В опросе приняло участие 636 человек (2013 2. - 336, 2018 2. - 300 человек). После обработки субъективных мнений респондентов, полученные эмпирические результаты соотнесли и сравнили со средними показателями по региону и в целом по стране, для чего были использованы материаль федеральной службб государственной статистики. В ходе исследования было выявлено, что подавляющее большинство сельского населения считаю место своего проживания экологически проблемным, отмечают негативное влияние на свое здоровье, как основную проблему указывают вывоз и утилизацию бытовых отходов, а так же ликвидацию несанкционированные свалки. Однако, сельские жстели не готовы активно участвовать в экологических мероприятия и задействовать государственные ресурсы для этих целей. Значимость социально-экономических проблем, для них, преобладает над экологическими.

Ключевые слова: анкетирование; экологические проблемы; сельские территории; устойчивое развитие; грантовая поддержка; экологический менеджмент.

DOI: $10.17586 / 2310-1172-2019-12-2-163-170$

\section{Ecological block of questionnaire research of rural areas residents}

\author{
Ph.D. Polukhina M G. redhvost@yandex.ru \\ Federal scientific center of leguminous and cereal crops \\ 302502, Russia, Orel region, Orel district, p/b Streletsky, Molodezhnaya str., 10
}

The object of study of rural population in 5 municipalities (Mtsenskiy, Soskovskiy, Shablykinskiy, Glazunovskiy, Bolkhovskiy) Orel region, representing all natural and economic zones (Western, Central and Southeast). The Subject of the Study. Environmental problems of rural residents who have a direct impact on the development of rural areas in a particular region. Purpose of research. To conduct a survey of rural residents to determine the impact of human economic activity on the environment, as well as the impact of the environmental situation on the sustainable development of rural areas, the quality of life of the villagers. Identify environmental problems and ways to solve them, as well as their importance for rural residents, with respect to social and economic problems. A questionnaire was developed to study the opinion of rural residents about the ecological state of the rural area and the directions of further development. Surveys of rural residents were conducted in two stages, in 2013 and 2018, to obtain data in dynamics. The survey was attended by 636 people (2013 - 336, 2018 - 300 people). After processing the subjective opinions of 
respondents, the empirical results were correlated and compared with the average for the region and the whole country, for which the materials of the Federal state statistics service were used. The study revealed that the vast majority of the rural population consider their place of residence environmentally problematic, note the negative impact on their health, as the main problem indicate the removal and disposal of household waste, as well as the elimination of unauthorized landfills. However, rural residents are not ready to actively participate in environmental activities and use public resources for these purposes. The importance of socio-economic problems, for them, prevails over environmental ones.

Keywords: survey; environmental problems; rural areas; sustainable development; grant support; environmental management.

\section{Введение}

Устойчивое развитие сельских территорий подразумевает под собой комплексное, одновременное развитие трех основных компонентов: социального, экономического и экологического. Каждый из них неразрывно связан с остальными и слабое развитие одного из них становится лимитирующим для других. Интенсивное развитие экономики, а так же не рациональное и экстенсивное использование окружающей среды в последние десятилетия привели к резкому увеличению числа экологических проблем, что автоматически привело к проблемам социальной сферы, в виде ухудшения качества жизни населения [1].

Данное исследование непосредственно посвящено экологическому компоненту (экологической деятельности и экологическим проблемам). Объектом исследования является экологическая обстановка сельских муниципальных образований.

Экологическая деятельность, являясь слагаемым устойчивого развития, сельских территорий направлена на рациональное природопользование, обеспечение высокого качества жизни людей на основе создания безопасной, здоровой среды обитания [2]. Кроме того, включает в себя формирование у населения экологической культуры, его экологическое образование и воспитание.

Ориентирами экологической деятельности выступают потребности человека в создании окружающей среды оптимальной для обитания современных и будущих поколений [3].

С позиций социальной экологии экологическая деятельность обусловлена взаимодействием трех групп факторов: природных, технических и социальных [4]. При этом ключевое значение имеют социальные факторы, которые рассматриваются на двух уровнях: макро (экологическая политика на уровне государства); микро (повседневные социальные взаимодействия индивидов) [5].

Экологическая деятельность непосредственно связана с применением рациональных способов организации общественного производства с целью снижения негативного воздействия на окружающую среду, подержания устойчивого развития. Различные виды экологической деятельности находят воплощение в реализации экологической политики государства [6].

В нашей стране экономическая политика базируется на ряде основополагающих актов федерального значения, таких как «Экологическая доктрина РФ», «Стратегия экологической безопасности Российской Федерации на период до 2025 года» ${ }^{2}$, «Основы государственной политики в области экологического развития РФ на период до 2030 г» ${ }^{3}$, Федеральные законы «Об охране окружающей среды» ${ }^{4}$. Для регулирования экологической деятельности, на уровне муниципальных образований, утвержден Федеральный закон «Об общих принципах организации местного самоуправления в Российской Федерации». Кроме того в каждом регионе имеются свои подзаконные акты, а так же региональные и муниципальные программы касающиеся охраны окружающей среды.

Все больше авторов используют понятие «социо-экологическая деятельность» подразумевающее взаимодействие индивидов с природой на основе экологических ценностей и норм. Целью социо-экологической деятельности при этом становятся исследования, охрана и возобновление природных ресурсов [7].

\footnotetext{
${ }^{1}$ Постановлением Правительства РФ от 31.08.2002 г. № 1225-р «Экологическая доктрина РФ». Интернет ресурс: http://www.zakonprost.ru/content/base/part/358498. Дата обращения - 10.04. 2019.

2 Указ Президента РФ от 19.04.2017 № 176 «О Стратегии экологической безопасности Российской Федерации на период до 2025 года». Интернет ресурс: https:/www.garant.ru/products/ipo/prime/doc/71559074/. Дата обращения - 10.04. 2019.

${ }^{3}$ Указом Президента РФ от 30.04.2012 г № 2423-р «Основы государственной политики в области экологического развития

РФ на период до 2030 г». Интернет ресурс: http://docs.cntd.ru/document/902388109. Дата обращения - 05.04. 2019.

${ }^{4}$ Федеральный закон от 10.01.2002 № 7-Ф3 (ред. от 31.12.2017) "Об охране окружающей среды". Интернет ресурс: https://base.garant.ru/12125350/ Дата обращения - 12.04. 2019.

${ }^{5}$ Федеральный закон Российской Федерации от 6 октября 2003 г. (ред. от 06.12. 2011) № 131-Ф3 «Об общих принципах организации местного самоуправления в Российской Федерации». Интернет ресурc: https://constitution.garant.ru/act/localgovernment/186367/. Дата обращения - 12.04. 2019.
} 
По мнению Дж. Форрестера, качество жизни в современном обществе напрямую зависит от уровня загрязнения окружающей среды и ряда других факторов. Автор концепции качества жизни считает, что высокий уровень развития промышленности ведет к росту плотности населения и загрязнению окружающей среды, затем, к росту стрессовых ситуаций и к более низкому качеству жизни [8]. С точкой зрения Дж. Форрестера в своих работах соглашаются такие ученые как Меренкова И.Н., Перцев В.Н., Новикова И.И изучающие вопросы устойчивого развития сельских территорий и улучшения качества жизни селян $[9,10,11]$.

По мнению Зенкова Н.А. невозможно только с помощью количественных индикаторов получить реальную картину относительно социальных, экономических процессов происходящих на селе [12]. Это же касается и экологической ситуации. Реальную картину можно получить, только применяя их в совокупности с качественными (экспертными) индикаторами - анкетированием, наблюдением, интервьюированием и опросом населения. Данная позиция полностью поддерживается работами Бондаренко Л.В., которая придает социологическим опросов не меньшую значимость, чем статистическим данным $[13,14]$.

\section{Основная часть}

Для определения экологической обстановки обследуемых территорий, возможных экологических проблем и степени их важности, а так же экологического поведения сельских жителей, респондентам было предложено ответить на ряд вопросов экологической тематики, табл. 1.

Таблица 1

\section{Распределение ответов респондентов на вопросы экологического характера}

\begin{tabular}{|l|c|c|c|c|c|c|}
\hline & \multicolumn{2}{|c|}{ Опрос 2013} & \multicolumn{2}{|c|}{ Опрос 2018} & \multicolumn{2}{|c|}{ Всего } \\
\cline { 2 - 7 } & $\begin{array}{c}\text { Кол-во } \\
\text { ответов }\end{array}$ & $\begin{array}{c}\text { Кол-во } \\
\text { ответов }\end{array}$ & $\begin{array}{r}\text { Кол-во } \\
\text { ответов }\end{array}$ & $\%$ \\
\hline 1. Оцените экологическое состояние Вашего населенного пункта? & 95 & 28,3 & 67 & 22,3 & 162 & 25,5 \\
\hline экологически благополучный & 124 & 36,9 & 129 & 43,0 & 253 & 39,8 \\
\hline $\begin{array}{l}\text { экологически проблемный, но проблемы не } \\
\text { значительные }\end{array}$ & 117 & 34,8 & 104 & 34,7 & 221 & 34,7 \\
\hline $\begin{array}{l}\text { экологически проблемный, проблемы значительные } \\
\text { (острые) }\end{array}$ & &
\end{tabular}

2. Укажите основные экологические проблемы Вашего населенного пункта?

(в \% от числа, считающих свой населенный пункт проблемным; возможны несколько вариантов ответа)

\begin{tabular}{|l|c|c|c|c|c|c|}
\hline загрязнение воды (реки, грунтовые воды и др) & 69 & 28,6 & 71 & 30,5 & 140 & 29,5 \\
\hline загрязнение почвы (агрохим. и пром. загрязнения) & 77 & 32,0 & 68 & 29,2 & 145 & 30,6 \\
\hline загрязнение воздух (загазованность, пром. выбросы) & 71 & 29,5 & 59 & 25,3 & 130 & 27,4 \\
\hline $\begin{array}{l}\text { антисанитарное состояние территории (бытовые отходы, } \\
\text { несанкционированные свалки и др). }\end{array}$ & 176 & 73,0 & 180 & 77,3 & 356 & 75,1 \\
\hline повышенный радиационный фон & 101 & 41,9 & 97 & 41,6 & 198 & 41,8 \\
\hline повышенный уровень шума & 28 & 11,6 & 32 & 13,7 & 60 & 12,7 \\
\hline $\begin{array}{l}\text { исчезновение отдельных животных и растений или } \\
\text { изменение их видового состава }\end{array}$ & 7 & 2,9 & 5 & 2,1 & 12 & 2,5 \\
\hline $\begin{array}{l}\text { распространение: карантинных и опасных растений, и } \\
\text { насекомых; болезней растений и животных }\end{array}$ & 86 & 35,7 & 91 & 39,1 & 177 & 37,3 \\
\hline $\begin{array}{l}\text { изменение рельефа (сокращение площади лесов, } \\
\text { обмеление водоемов, эрозия почв и др.) }\end{array}$ & 15 & 6,2 & 18 & 7,7 & 33 & 7,0 \\
\hline з. эзолеге & & &
\end{tabular}

3. Экологическое состояние места проживания, негативно сказывается на Вашем здоровье?

\begin{tabular}{|l|c|c|c|c|c|c|}
\hline да & 238 & 70,8 & 231 & 77 & 469 & 73,7 \\
\hline нет & 98 & 29,2 & 69 & 23 & 167 & 26,3 \\
\hline
\end{tabular}

4. Какие системы и органы Вашего тела больше всего подверглись негативному воздействию? (в \% от числа считающих, что экологическое состояние населенного пункта негативно влияет на здоровье; возможны несколько вариантов ответов)

\begin{tabular}{|l|c|c|c|c|c|c|}
\hline дыхательная система (ринит, кашель и др.) & 24 & 10,1 & 29 & 12,6 & 53 & 11,3 \\
\hline кожные покровы (дерматит и др.) & 32 & 13,4 & 41 & 17,7 & 73 & 15,6 \\
\hline неврология (головные боли, нарушения сна и др.) & 123 & 51,7 & 144 & 62,3 & 267 & 56,9 \\
\hline пищеварительная система & 21 & 8,8 & 10 & 4,3 & 31 & 6,6 \\
\hline другое & 64 & 26,9 & 72 & 31,2 & 136 & 29,0 \\
\hline
\end{tabular}




\begin{tabular}{|c|c|c|c|c|c|c|}
\hline НО БЫ делаете для охраны окружающеи сы & & MDT 1 & 年 & aprat & 然 & \\
\hline $\begin{array}{l}\text { выбрасываю мусор только в специально отведенных } \\
\text { местах. }\end{array}$ & 278 & 82,7 & 264 & 88 & 542 & 85,2 \\
\hline собираю за собой мусор после поездок на природу & 259 & 77,1 & 247 & 82,3 & 506 & 79,6 \\
\hline $\begin{array}{l}\text { участвую в субботниках, мероприятиях по уборке } \\
\text { территории }\end{array}$ & 176 & 52,4 & 198 & 66 & 374 & 58,8 \\
\hline $\begin{array}{l}\text { пытаюсь не пользоваться полиэтиленовыми пакетами, } \\
\text { заменяю их тканевыми и многоразовыми } \\
\text { полиэтиленовыми сумками }\end{array}$ & 98 & 29,2 & 120 & 40 & 218 & 34,3 \\
\hline экономно расходую воду, газ, электричество и т. д. & 156 & 46,4 & 176 & 58,7 & 332 & 52,2 \\
\hline $\begin{array}{l}\text { сортирую мусор (бумага, пластик, пищевые отходы } \\
\text { и т. п.) }\end{array}$ & 23 & 6,8 & 17 & 5,7 & 40 & 6,3 \\
\hline ничего из перечисленного & 12 & 3,6 & 7 & 2,3 & 19 & 3,0 \\
\hline $\begin{array}{l}\text { 6. Какие меры, по Вашему мнению, необходимо пре } \\
\text { состояния сельских территорий? (возможны несколь }\end{array}$ & & & & & & \\
\hline $\begin{array}{l}\text { установить контейнерные площадки, организовать } \\
\text { регулярный вывоз мусора }\end{array}$ & 177 & 52,7 & 201 & 67 & 378 & 59,4 \\
\hline устранить несанкционированные свалки & 198 & 58,9 & 212 & 70,7 & 410 & 64,5 \\
\hline $\begin{array}{l}\text { посадка зеленых насаждений (улицы, пром. зоны, вдоль } \\
\text { дорог и автотрасс и др.) }\end{array}$ & 67 & 19,9 & 54 & 18,0 & 121 & 19,0 \\
\hline $\begin{array}{l}\text { установка пром. предприятиями фильтров на стоки, } \\
\text { газоуловители, техническая модернизация производства }\end{array}$ & 98 & 29,2 & 81 & 27,0 & 179 & 28,1 \\
\hline $\begin{array}{l}\text { усиление государственного контроля за соблюдением } \\
\text { экологического законодательства предприятиями }\end{array}$ & 85 & 25,3 & 104 & 34,7 & 189 & 29,7 \\
\hline переработка мусор, а не хранение его на полигоне & 120 & 35,7 & 111 & 37,0 & 231 & 36,3 \\
\hline борьбе с Борщевиком Сосновского & 69 & 20,5 & 65 & 21,7 & 134 & 21,1 \\
\hline развитие инженерной инфраструктуры села & 115 & 34,2 & 124 & 41,3 & 239 & 37,6 \\
\hline отлов бродячих животных & 64 & 19,0 & 58 & 19,3 & 122 & 19,2 \\
\hline
\end{tabular}

Источник. Составлено автором

Анализ полученных ответов показал, что только 25,5\% сельских жителей считают свою местность экологически благополучным. Причем число, так считающих, сокращается (на 6 п.п. по сравнению 2018 с 2013 годом). Все больше респондентов отмечают незначительные экологические проблемы, 43\% от опрошенных в 2018 г. против $36,9 \%$ в 2013 г.

Число респондентов считающих, что экологические проблемы значительные и даже острые стабильно $34,7 \%$ и не меняется по годам.

К ним в большей степени относятся сельские жители, проживающие вблизи крупных предприятий, несанкционированных свалок и пр. Из имеющихся объектов, расположенных на обследуемой территории, с наиболее агрессивной деятельностью можно выделить ЗАО «Сахарный комбинат «Отрадинский» (Мценский район), ООО «Мценский спиртоводочный комбинат «Орловская крепость» (Мценский район). Для вышеозначенных объектов перерабатывающей промышленности характерны такие отходы как дефекационная грязь, барда, жом, меласса, их бесконтрольный вывоз на сельхозугодья и сброс в реки приводит к биологическому загрязнению. Кроме того в почву и водоемы происходит попадание сточных вод с производства, пестицидов и прочего, так же в почву попадают горюче смазочные материалы; происходит загрязнение воздуха испарениями отходов биологического происхождения, а так же пылью $\mathrm{CaCO}_{3}$ от высыхания дефекационной грязи и т.д. [1]. Кроме того, в Мценский район и вблизи самого г. Мценска находятся свалка коммунальностроительных отходов в карьере на землях сельскохозяйственного назначения и крупный полигон ТБО. Так же, кроме означенных объектов, повсеместно имеются стихийные свалки.

Далее, на вопрос анкеты «Укажите основные экологические проблемы Вашего населенного пункта?» отвечали 74,5\% респондентов считающих, что населенный пункт их проживания имеет экологически проблемный.

Таким образом, выяснилось, что наиболее волнующими экологическими проблемами для населения являются:

На антисанитарное состояние территории приходится 75,1\% ответов респондентов. Сравнивая результаты 2013 и 2018 годов можно заметить, что в 2018 году данный ответ выбирали на 5,3 п.п. чаще. Стихийные свалки возникают повсеместно, при отсутствии в населенном пункте контейнерных площадок, их недостаточном количестве или не регулярном вывозе мусора. Наличие контейнерных площадок, к сожалению, не является 
гарантией чистоты, зачастую вывоз мусора осуществляется только из контейнеров. Сельские жители жалуются, что вывоз мусора, не поместившегося в контейнер, не происходит, т.е. контейнерная площадка превращается в свалку. Происходит накопление метана, сероводорода, аммиака, оксида углерода, бензола в воздухе; накоплении в почве и попадании в грунтовые воды тяжелых металлов, нефтепродуктов, нитратов, гидрокарбонатов и др.;

Повышенный радиационный фон волнует $41,8 \%$ респондентов, их процент стабилен и не изменяется по годам. Такая обеспокоенность легко объяснима, населенные пункты три из пяти обследуемых районов (Болховский, Сосковский, Шаблыкинский) находящихся в границах зоны радиоактивного загрязнения вследствие катастрофы на чернобыльской АЭС

Распространение карантинных и опасных растений, болезней растений и животных выбрали $37,3 \%$ опрошенных. Процент респондентов выбравших данный ответ вырос в 2018 году на 3,4 п.П. по сравнению с 2013 годом. Чаще всего опрошенные выражали опасения по поводу увеличения площадей зараженных Борщевиком Сосновского и частых вспышек чумы свиней.

Загрязнение воды, почвы, воздуха волнует от 27,4 до $30,6 \%$ респондентов. В качестве источников загрязнения выступают не только сельское хозяйство и перерабатывающая промышленность, транспорт, но и недостаточно развитая инженерная инфраструктура. Из опрошенных 636 человек $39 \%$ проживают в отдельной квартире или частном доме с частичными удобствами и $2,3 \%$ - в частном доме без удобств. Сельский жилищный фонд по уровню благоустройства и комфортности в значительной степени уступает городскому. В России центральную канализацию, на 2015 год, имело $57 \%$ сельских населенных пунктов ${ }^{7}$, в Орловской области этот показатель составил $-50,3 \%$. Необходимо заметить, что сельские канализационные сети в значительной степени изношены и нуждаются в замене (33\%) и как правило, не охватывают полностью населенный пункт [15].

На вопрос «Экологическое состояние места проживания, негативно сказывается на Вашем здоровье?» 73,7\% респондентов ответили «Да». Этим респондентам, далее было предложено указать на какие системы и органы их тела больше всего подверглись негативному воздействию. Чаще всего респонденты указывали на неврологические нарушения (частые головные боли) - 56,9\% и кожные заболевания (дерматиты разной этиологии) - 15,6\%. Ответ «другое» выбрало $29 \%$ опрошенных. Под «другим» респонденты чаще всего имели в виду: онкологические заболевания; общее недомогание; отсутствие энергии; низкий, по их мнению, иммунитет; частую заболеваемость ОРЗ и ОРВИ. Оценивая общую заболеваемость городского населения по стране можно отметить ее сокращение на 7,5\% за период с 2013 по 2015 год. В то же время заболеваемость сельского населения выросла на 1,8\% за тот же период и составила в 2015 году 12317,5 случаев на 10 тыс. человек населения, заболеваемость городского населения составила 3703,2 случаев на 10 тыс. человек населения ${ }^{8}$.

Для выяснения экологической активности сельского населения респондентам был предложен вопрос «Что лично Вы делаете для охраны окружающей среды?» с возможностью нескольких вариантов ответов.

Анализируя полученные ответы можно заключить, что экологическая активность селян ограничивается выбросом мусора в специально отведенных местах - 85,2\%, собиранием за собой мусор после поездок на природу $-79,6 \%$ и участием в субботниках $-58,8 \%$. Экономно расходуют воду, газ и электричество $52,2 \%$ респондентов. Однако не из соображений экологии, а из-за их высокой коммунальной стоимости, по словам многих опрошенных.

Сортировку мусора практически ни кто из опрошенных селян не производит, только 6,3\%. Укажем, что данное мероприятие для Орловской области, к сожалению, не актуально, т.к. централизованный сбор мусора осуществляется без разделения.

Респондентам было предложено ответить на вопрос: «Какие меры, по Вашему мнению, необходимо предпринять для улучшения экологического состояния сельских территорий?» (возможны несколько вариантов ответов), распределение ответов представлено в табл. 1 и на рис. 1.

\footnotetext{
${ }^{6}$ Постановление Правительства Российской Федерации от 8 октября 2015 г. № 1074 "Об утверждении перечня населенных пунктов, находящихся в границах зон радиоактивного загрязнения вследствие катастрофы на Чернобыльской АЭС" Интернет ресурс: https://base.garant.ru/71216726/. Дата обращения - 12.04. 2019.

${ }^{7}$ О состоянии сельских территорий в Российской Федерации в 2015 году. Ежегодный доклад по результатам мониторинга: науч. изд. - М.: ФГБНУ «Росинформагротех», 2017, вып. 3-й. - 348c.

${ }^{8}$ Сельское здравоохранение России 2016г. в 2015 Интернет ресурc:https://www.rosminzdrav.ru/ministry/61/22/stranitsa979/statisticheskaya-informatsiya-minzdrava-rossii. Дата обращения 19.12.2018.
} 


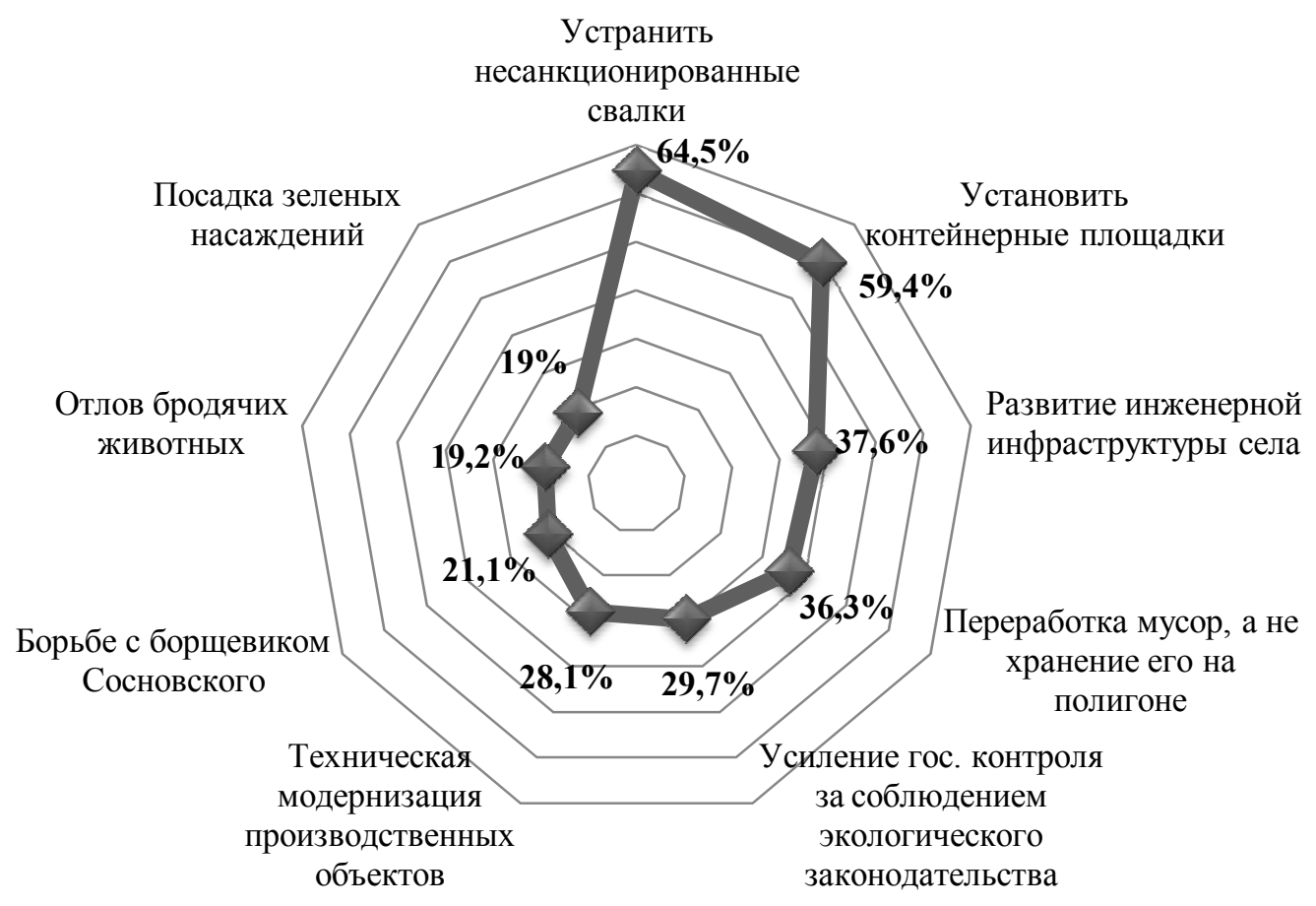

Источник. Расчет автора

Рис. 1. Меры необходимые для улучшения экологического состояния сельских территорий, по мнению респондентов, \%

К первостепенным мерам для улучшения экологического состояния сельских территорий большинство опрошенных отнесли: устранить несанкционированные свалки $(64,5 \%)$ и установить контейнерные площадки, организовать регулярный вывоз мусора $(59,4 \%)$. Чуть больше трети опрошенных считают что необходимо развивать инженерную инфраструктуру села, т.е устранение выгребных ям, проведение центральной канализации $(37,6 \%)$ и перерабатывать мусор, а не хранить его на полигонах $(36,3 \%)$.

Стоит упомянуть, что государство со своей стороны, в рамках реализации федеральной целевой программы «Устойчивое развитие сельских территорий на 2014-2017 годы и на период до 2020 года» и государственной программы «Устойчивое развитие сельских территорий Орловской области на 2014 - 2017 годы и на период до 2020 года» ${ }^{9}$ осуществляет грантовую поддержку местных инициатив предоставляя гранты в размере до $60 \%$ от общей стоимости проекта, в пределах 2 млн. руб. на безвозвратной основе органу местного самоуправления или органу территориального общественного самоуправления сельского поселения на реализацию общественно значимых некоммерческих проектов с участием граждан, проживающих в сельской местности, по трем приоритетным направлениям поддержки: создание и обустройство зон отдыха, спортивных и детских игровых площадок; сохранение и восстановление природных ландшафтов (очистка водоемов, береговых зон, лесных насаждений, историко-культурных памятников; поддержка национальных культурных традиций, народных промыслов и ремесел ${ }^{10}$. За пять лет (2014-2018 годы) осуществления грантовой поддержке местных инициатив сельских граждан, проживающих в сельской местности Орловской области было реализовано 12 проектов и только один из них касался улучшения экологического состояния (очистка водоемов с. Остров Островского сельского поселения Ливенского района).

На вопрос анкеты «Что, на ваш взгляд, в первую очередь необходимо построить или улучшить в вашем населенном пункте?», за первоочередность решения проблемы вывоза мусора высказалось только 5,9\% опрошенных.

9 Постановлением Правительства Орловской области от 4 декабря 2013 года № 411 "Об утверждении государственной программы Орловской области "Устойчивое развитие сельских территорий Орловской области на 2014 - 2017 годы и на период до 2020 года". Интернет ресурс: http://docs.cntd.ru/document/460219152. Дата обращения - 12.04. 2019.

${ }^{10}$ Рекомендации по применению механизма грантовой поддержки местных инициатив граждан, проживающих в сельской местности: информ.-метод. Изд. - М.: ФГБНУ «Росинформагротех», 2016. - 88 с. 
По многим параметрам жизнь в сельской местности уступает городской. Для того чтобы она стала более комфортной и благоприятной, важно было выяснить у сельских жителей, что для этого нужно изменить. С этой целью респондентам было предложено проранжировать общественные нужды по степени важности. По мнению респондентов наиболее важными общественными нуждами являются обеспеченность работой, повышение оплаты труда и наличие собственного благоустроенного жилья. Менее значительны по степени важности, по мнению респондентов, оказались развитие социальной инфраструктуры, комфортные условия жизни и пр., охрана окружающей среды оказалась на десятом месте из двенадцати возможных.

\section{Выводы}

Таким образом, подводя итоги можно сказать, что: вопросы экологического состояния сельских территорий волнуют их жителей, однако, решение экологических проблем отходят на второе место по важности, в сравнении с накопившимися социально-экономическими проблемами сельских территорий, другими словами, проекты экологической направленности не имеют для сельских жителей актуальности, пока не будут реализованы первичные потребности. Так, согласно пирамиде потребностей А. Маслоу [16], нерешенные вопросы формирования доходов семьи более актуальны аспектов экологической безопасности. Однако, не решение экологических проблем может повлечь за собой более серьёзные проблемы, связанные со здоровьем и демографией.

\section{Литература}

1. Полухина М.Г. Инженерная инфраструктура как элемент развития сельских территорий // Вестник Московского городского педагогического университета. 2018. №1(15). С 33-47.

2. Бусыгин А.Г., Макеева Е.Д., Павловский В.А. Роль дисциплины «экологические организации и движения» в формировании общекультурных профессиональных компетенций студентов-экологов второго уровня подготовки (магистров) // Балтийский гуманитарный журнал. 2016. Т. 5. № 3. С. 99-101.

3. Краснобаев Ю.П. Современные подходы к сохранению биологического разнообразия в границах одной из крупнейших агломераций России - Самарско-Тольяттинской (на примере Жигулевского заповедника) // Карельский научный журнал. 2016. Т. 5.№ 3. С. 56-58.

4. Бабкин B.O. Социальная экология как новая развивающаяся дисциплина и её взаимосвязь с экологией человека // Известия Оренбургского государственного аграрного университета. 2014. № 3. C. $183-186$.

5. Киприянова М.A. О месте социальной экологии в социологии // Историческая и социальнообразовательная мысль. 2013. № 2. С. 152-157.

6. Зазнобина Н.И., Молькова Е.Д., Гелашвили Д.Б. Сравнительная динамика социо-экологоэкономических систем России и некоторых стран большой двадцадки (G20) на основе обобщенной функции желательности // Карельский научный журнал. 2016.Т. 5. № 3. С. 45-48.

7. Шилова В.С. Социально-экологическая деятельность: теоретические предпосылки изучения // Научный результат. Серия: Педагогика и психология образования. 2014. № 1. С. 101-106.

8. Форрестер Дж. Мировая динамика - М.: Наука, 1978.

9. Меренкова И.Н., Перцев В.Н., Новикова И.И. Концептуальные положения по формированию стратегии жизнеобеспечения сельского населения. - Воронеж, 2012. - 48 с.

10. Перцев B.Н. Устойчивое развитие сельских территорий муниципального района: дис. ... канд. экон. наук. - Воронеж. - 2011.

11. Новикова И.И. Многофункциональность сельской местности и сельского хозяйства // Актуальные проблемы современной науки : сб. матер. междунар. науч.-практ. конф. - Тамбов : Издво Першина P.B., 2011. - C. 193-198.

12. Зенкова Н.А. Система индикаторов социально-экономического развития городских и сельских поселений:дис. ... канд. экон. наук. - М. - 2010.

13. Бондаренко Л.В. Развитие сельских территорий: оценки, мнения, ожидания // Социологические исследования. 2016. №3 (383). С. 76-82.

14. Бондаренко Л.В. Развитие сельских территорий: оценки, мнения, ожидания // Агропродовольственная политика России. 2017. №11 (71). С. 13-16.

15. Полухина М.Г. Инженерная инфраструктура как элемент развития сельских территорий // Вестник Московского городского педагогического университета. 2018. №1(15). С 33-47.

16. Maslow A.H. Motivation and Personality. - New York: Harpaer \& Row, 1954. 


\section{References}

1. Poluhina M.G. Inzhenernaya infrastruktura kak element razvitiya sel'skih territorij // Vestnik Moskovskogo gorodskogo pedagogicheskogo universiteta. 2018. №1(15). S 33-47.

2. Busygin A.G., Makeeva E.D., Pavlovskij V.A. Rol' discipliny «ekologicheskie organizacii i dvizheniya» v formirovanii obshchekul'turnyh professional'nyh kompetencij studentov-ekologov vtorogo urovnya podgotovki (magistrov) // Baltijskij gumanitarnyj zhurnal. 2016. T. 5. № 3. S. 99-101.

3. Krasnobaev YU.P. Sovremennye podhody k sohraneniyu biologicheskogo raznoobraziya $\mathrm{v}$ granicah odnoj iz krupnejshih aglomeracij Rossii - Samarsko-Tol'yattinskoj (na primere ZHigulevskogo zapovednika) // Karel'skij nauchnyj zhurnal. 2016. T. 5.№ 3. S. 56-58.

4. Babkin V.O. Social'naya ekologiya kak novaya razvivayushchayasya disciplina i eyo vzaimosvyaz' s ekologiej cheloveka // Izvestiya Orenburgskogo gosudarstvennogo agrarnogo universiteta. 2014. № 3. S. 183-186.

5. Kipriyanova M.A. O meste social'noj ekologii v sociologii // Istoricheskaya i social'no-obrazovatel'naya mysl'. 2013. № 2. S. 152-157.

6. Zaznobina N.I., Mol'kova E.D., Gelashvili D.B. Sravnitel'naya dinamika socio-ekologo-ekonomicheskih sistem Rossii i nekotoryh stran bol'shoj dvadcadki (G20) na osnove obobshchennoj funkcii zhelatel'nosti // Karel'skij nauchnyj zhurnal. 2016.T. 5. № 3. S. 45-48.

7. SHilova V.S. Social'no-ekologicheskaya deyatel'nost': teoreticheskie predposylki izucheniya // Nauchnyj rezul'tat. Seriya: Pedagogika i psihologiya obrazovaniya. 2014. № 1. S. 101-106.

8. Forrester Dzh. Mirovaya dinamika - M.: Nauka, 1978.

9. Merenkova I.N., Percev V.N., Novikova I.I. Konceptual'nye polozheniya po formirovaniyu strategii zhizneobespecheniya sel'skogo naseleniya. - Voronezh, 2012. - $48 \mathrm{~s}$.

10. Percev V.N. Ustojchivoe razvitie sel'skih territorij municipal'nogo rajona: dis. ... kand. ekon. nauk. - Voronezh. 2011.

11. Novikova I.I. Mnogofunkcional'nost' sel'skoj mestnosti i sel'skogo hozyajstva // Aktual'nye problemy sovremennoj nauki : sb. mater. mezhdunar. nauch.-prakt. konf. - Tambov : Izdvo Pershina R.V., 2011. - S. 193-198.

12. Zenkova N.A. Sistema indikatorov social'no-ekonomicheskogo razvitiya gorodskih i sel'skih poselenij:dis. ... kand. ekon. nauk. - M. -2010.

13. Bondarenko L.V. Razvitie sel'skih territorij: ocenki, mneniya, ozhidaniya // Sociologicheskie issledovaniya. 2016. №3 (383). S. 76-82.

14. Bondarenko L.V. Razvitie sel'skih territorij: ocenki, mneniya, ozhidaniya // Agroprodovol'stvennaya politika Rossii. 2017. №11 (71). S. 13-16.

15. Poluhina M.G. Inzhenernaya infrastruktura kak element razvitiya sel'skih territorij // Vestnik Moskovskogo gorodskogo pedagogicheskogo universiteta. 2018. №1(15). S 33-47.

16. Maslow A.H. Motivation and Personality. - New York: Harpaer \& Row, 1954. 